\title{
Hormonal treatment of acne vulgaris: an update
}

This article was published in the following Dove Press journal:

Clinical, Cosmetic and Investigational Dermatology

2 September 2016

Number of times this article has been viewed

\section{Mohamed L Elsaie \\ Department of Dermatology and Venereology, National Research \\ Centre, Cairo, Egypt}

Correspondence: Mohamed L Elsaie National Research Centre, 15 Tarablos Street Off Abbas Akkad Street, Nasr city II37I, Cairo, Egypt

Tel +20109950 II69

Email Egydoc77@yahoo.com

\begin{abstract}
Acne vulgaris is a common skin condition associated with multiple factors. Although mostly presenting alone, it can likewise present with features of hyperandrogenism and hormonal discrepancies. Of note, hormonal therapies are indicated in severe, resistant-to-treatment cases and in those with monthly flare-ups and when standard therapeutic options are inappropriate. This article serves as an update to hormonal pathogenesis of acne, discusses the basics of endocrinal evaluation for patients with suspected hormonal acne, and provides an overview of the current hormonal treatment options in women.
\end{abstract}

Keywords: acne, hormones, hyperandrogenism

\section{Introduction}

Acne vulgaris affects $\sim 80 \%$ of adolescents and young adults aged $11-30$ years. The majority of affected individuals remit before the third decade of age, leaving the rest with an unpredictable course throughout their lives. ${ }^{1}$ The principal hallmarks of acne include follicular hyperproliferation and plugging, extensive formation of sebum, activity of Propionibacterium acnes, and inflammation. ${ }^{2}$ Standardization of acne treatments is impossible with the huge amount of data and research being released constantly. ${ }^{3}$ Hormonal therapies are reserved not only for patients with biochemical markers of hyperandrogenism but also for the severe, resistant cases as well as for those patients who show an unpredictable course and high frequency of acne bouts without hyperandrogenemia. ${ }^{4} \mathrm{~A}$ decent comprehension of the hormonal milieu in the human body can pinpoint toward an optimal, faster, and more appropriate treatment of acne.

\section{Acne pathogenesis}

Acne is a follicular unit disease. It involves pathologically overproduction of serum, abnormal follicular keratinization, formation of $P$. acnes biofilms and colonies, and finally the release of proinflammatory mediators to the skin. ${ }^{5}$

While the formation of the microcomedones is the first symptom of acne, the exact reason for triggering such reaction remains unknown. ${ }^{6}$ Acne-prone individuals have larger sized sebaceous glands that are stimulated at the time of puberty. ${ }^{7}$ Dihydrotestosterone (DHT) was shown to be more selective to sebocytes of the face but not the leg. This determines the predilection of acne lesions to certain areas on the body. ${ }^{8}$ Several pathways and hormones beside androgens regulate the activity of sebocytes, for example, peroxisome proliferator-activated receptors, substance $\mathrm{P}$ receptors, 
$\alpha$-melanocyte-stimulating hormone, insulin-like growth factor, corticotropin-releasing hormone (CRH), vitamin D, and ectopeptidases. ${ }^{9-11}$

In the meantime, while sebum generation is abundant, failure to shed intrafollicular keratinocytes results in obstruction of the pilosebaceous units with sebum and keratolytic debris resulting in larger comedones. This, in turn, leads to plugging and studding of the follicular units with the pathogenic $P$. acnes leading to an exaggerated inflammatory response. ${ }^{12}$ A number of agents are secreted by $P$. acnes and include the enzymes lipase and protease that manage to disrupt and degrade the follicular wall and initiate a cascade of inflammatory events and release of chemotactic factors. ${ }^{13}$

An additional area of interest that has recently emerged is the action of vitamin D in the skin. The pilosebaceous unit is capable of metabolizing and producing provitamin D in the skin. Vitamin D deficiency may be linked to the pathogenesis of insulin resistance and the metabolic syndrome in polycystic ovary syndrome (PCOS). Furthermore, vitamin D analogs may potentially be useful in normalizing sebaceous gland physiology in patients with acne. ${ }^{14}$

\section{Hormones implicated in acne pathogenesis}

Hormones implicated in acne pathogenesis include androgens, estrogens, progesterone, insulin and insulin-like growth factor-1, CRH, adrenocorticotropic hormone (ACTH), melanocortins, glucocorticoids, and growth hormone $(\mathrm{GH}){ }^{15}$

\section{Androgens}

Androgens represent the most important of all hormones regulating sebum production. ${ }^{16}$ As of puberty, androgens stimulate sebum production and acne formation in both sexes. This androgen-dependent secretion of sebum is mediated by potent androgens such as testosterone and DHT and likewise with weaker androgens. The adrenal glands and ovaries represent a source for dehydroepiandrosterone (DHEA) and androstenedione production. DHEA is predominantly produced by the adrenal glands, while androstenedione is produced by the ovaries and adrenal glands in equal proportions. Of interest, $5 \alpha$-reductase enzyme in the infundibular sebocytes can convert the testosterone to the 5-10 times more active DHT. ${ }^{13}$

\section{Progesterone}

Progesterone inhibits $5 \alpha$-reductase required to convert testosterone to the more potent DHT. Menstrual flare and sebum exacerbations are caused by progesterone whose receptors are expressed in basal epidermal keratinocytes only. ${ }^{4}$

\section{Estrogen}

High-dose estrogen exerts a negative feedback on the gonadal axis. This results in the reduction of sebaceous gland size and concomitantly reduced sebum formation. Estrogen receptor (ER) $\alpha$ is localized in sebocytes only, while ER $\beta$ is found to be highly expressed in sebocytes, keratinocytes, melanocytes, dermal fibroblasts, endothelial cells, and adipocytes. ${ }^{17}$

Estrogen may influence sebum formation through 1) negative feedback inhibition of gonadal axis, 2) increased production of sex hormone-binding globulin (SHBG) by the liver, thereby decreasing free serum testosterone, 3) counteracting directly the action of testosterone in the sebocytes, and 4) influencing the genetic regulation of sebaceous gland and sebocyte formation. ${ }^{18}$

\section{Insulin and insulin growth factor I}

Insulin stimulates the growth and maturation of sebaceous glands. This action is mediated through upregulation of GH receptors on the sebocytes by insulin. ${ }^{19}$ Moreover, insulin inhibits SHBG production from the liver and further plays a positive feedback effect on adrenal and ovarian androgenesis. The controversial link between diet and acne can be explained by the fact that highly glycemic index foods result in insulin release and in turn excess androgen and sebum production. ${ }^{20}$

\section{Corticotrophin-releasing hormone}

$\mathrm{CRH}$ secreted by the hypothalamus is converted to proopiomelanocortin in the anterior pituitary. Proopiomelanocortin is converted to ACTH and melanocyte-stimulating hormone, which upregulate the cortisol production cycle. $\mathrm{CRH}$ targets the sebaceous glands and induces lipogenesis by enhancing androgen bioavailability and by stimulating the conversion of DHEA to testosterone. ${ }^{21}$

\section{Melanocortins}

Melanocortin is one of the breakdown products of proopiomelanocortin. Two different receptors MC-1R and MC-5R are expressed by the sebocytes in the sebaceous glands that regulate the sebocyte differentiation and lipogenesis. ${ }^{22}$

\section{Glucocorticoids}

Steroids are thought to increase acne eruptions (steroid acne) through their increased Toll-like receptor 2 gene expressions and further release of the proinflammatory mediators. ${ }^{23}$ 


\section{Pituitary hormones}

1. ACTH: sebum production stimulator. ${ }^{16}$

2. GH: it activates the differentiation of the sebocytes and stimulates the conversion of testosterone to DHT by $5 \alpha$-reductase. ${ }^{24}$

3. LH: androgens are secreted by the ovaries under regulation of LH. ${ }^{16}$

4. Prolactin: prolactin receptors are well expressed in the adrenal glands. In cases of hyperprolactinemia, adrenal androgens are secreted in an increased manner and contribute to the rapid formation of acne pimples. ${ }^{24}$

\section{Endocrinal evaluation in patients with suspected hormonal acne}

Hormonal evaluation is not mandatory for those who experience short bouts of onset and offset or those who respond well to standard treatments. However, in the more resistant cases and for those who fail to respond to conventional therapies, endocrinal evaluation is an important tool to consider as well as in the following cases: ${ }^{8}$

1. Late-onset acne (presenting in the third decade)

2. Therapy-resistant acne

3. Prepubertal acne

4. Stress-exacerbated acne

5. Premenstrual onset

6. Hyperandrogenism

7. Signs of virilization (clitiromegaly, deepened voices, and masculine features)

8. PCOS

9. Signs of hyperinsulinemia (obesity in the trunks, skin tags, and acanthosis)

10. Distribution of the acne lesions. It is well recognized that hormonal acne concentrates in the lower third of the face along the chin and jaw lines.

Hyperandrogenism in females can be caused by ovarian or adrenal factors. PCOS and ovarian tumors (benign or malignant) are among the ovarian causes while adrenal hyperplasia (congenital or noncongenital) and adrenal tumors (benign or malignant) account for the adrenal causes. ${ }^{24}$ Of all causes, PCOS accounts for $>90 \%$ of the overall causes of hyperandrogenism in women and comprises an array of endocrinal abnormalities with or without cyst formation. High levels of androgens and estrogens in laboratory investigations with polycystic ovaries in ultrasonographic studies along with the clinical manifestations of anovulation presenting with oligo/amenorrhea are the hallmarks of
PCOS. ${ }^{25}$ Hyperinsulinemia is another feature that exists as a cofactor or an extrinsic factor in cases of PCOS. Insulin has a direct stimulant effect on androgenesis besides inhibiting the SHBG synthesis by the liver. ${ }^{26}$ Of interest, $50 \%$ of cases with ovarian hyperandrogenism experience an existing functional adrenal hyperandrogenism. ${ }^{27}$

It is important to remember that many patients with hormonal acne might not have a raised level of circulating testosterone in their blood and that some women with raised androgen levels can still have normal menstruation. This is primary because only a small portion of the testosterone $(1 \%-2 \%)$ is being free and able to bind to the androgen receptors (ARs) to induce action, so unless free testosterone is measured separately, total testosterone level may still be normal in spite of obvious hyperandrogenism signs. ${ }^{28}$ Signs of hyperandrogenism despite normal levels of both total and free testosterone can be explained by the fact that there is an increased sensitivity of the receptors to androgen at the pilosebaceous unit or an increased activity of the $5 \alpha$-reductase enzyme resulting in overproduction of DHT, which is five times more potent than testosterone. ${ }^{29}$

\section{Laboratory tests in patients with suspected hormonal acne}

For patient's signs of hyperandrogenism, failure to respond to conventional therapies, and with irregular menses, endocrinal evaluation is required at the early menstrual phase (follicular phase). Other hormonal treatments such as oral contraceptives should be terminated and stopped 1 month before laboratory investigations to avoid false results. ${ }^{8}$

1. Testosterone (free and total): minimal to modest elevations of $<200 \mathrm{ng} / \mathrm{dL}$ are suggestive of a benign cause of ovarian or adrenal cause while above this level; neoplasia of ovarian or adrenal origin should be suspected. ${ }^{30}$

2. Androstenedione: secreted equally by ovaries and adrenals and follows a circadian rhythm making early morning samples, the best to analyze. ${ }^{30}$

3. DHEA: high levels of DHEA $>8,000 \mathrm{ng} / \mathrm{dL}$ and dehydroepiandrosterone sulfate (DHEAS) should raise concern of adrenal tumors, while levels of DHEAS $(4,000-$ $8,000 \mathrm{ng} / \mathrm{dL}$ ) indicate benign adrenal hyperplasia. ${ }^{30}$

4. SHBG: decreased levels of SHBG lead to free unbound testosterone in excess, resulting in more manifested signs. ${ }^{31}$

5. Prolactin: elevated prolactin could point out to hypothalamic or pituitary causes for further assessment and investigation. $^{8}$ 
6. 17-Hydroxy progesterone: elevated (>200 ng/dL) in congenital adrenal hyperplasia or nonclassic congenital adrenal hyperplasia due to deficiency or absence of $21 \alpha$-hydroxylase. ${ }^{8}$

7. Luteinizing hormone ( $\mathrm{LH})$ : follicle-stimulating hormone (FSH) ratio: a ratio of $>2$ is indicative of possible PCOS. ${ }^{8}$

8. Fasting and postprandial insulin: overweight and obese patients should be checked for insulin levels. ${ }^{31}$

9. Serum cortisol: high levels are an indication of adrenal neoplasia. ${ }^{31}$

For further evaluation, ACTH stimulation or dexamethasone suppression test should be carried out. Ovarian sources of androgen will be reluctant to respond for both tests while adrenal sources would increase following the ACTH stimulation and decrease in response to dexamethasone suppression test. ${ }^{8}$

\section{Hormonal therapy}

Acne presenting with cysts, nodules, sudden onset, and widely dispersed lesions is often indicative of excess androgens. As mentioned earlier, hormonal imbalance should still be considered even in women with a normal menstrual period. ${ }^{4}$ Hormonal therapies are reserved not only for patients with biochemical markers of hyperandrogenism but also for the severe, resistant cases as well as for those patients who show an unpredictable course and high frequency of acne bouts without hyperandrogenemia and with resistance to conventional therapies (Table 1$){ }^{8}$
Similarly for those patients with contraindication to other modes of therapy or to those women thinking of contraception, hormonal treatments can be of choice. However, hormonal treatment is not indicated as monotherapy. ${ }^{18} \mathrm{In}$ general terms, the objectives of hormonal therapy in acne are to 1) suppress androgen production from ovaries and adrenals and pituitary and 2) inhibit ARs on sebaceous glands. ${ }^{32}$

The European guidelines on acne therapy recommend hormonal treatment along with topical or systemic antibiotics in severe pustular and moderate nodulocystic acne cases as an alternative to starting therapy with isotretinoin. In the nodular or conglobate type of acne, antibiotics along with hormonal treatment are a recommendation of choice. In the mildest type of acne (comedonal), it is absolutely contraindicated to use hormones (Table 2). ${ }^{11}$

Hormonal therapy is effective in acne despite elevated androgen levels or not. It is frequently used as a combination and not a stand-alone therapy. It can be synergistically combined with antibiotics, benzoyl peroxide, azelaic acid,

Table I Indications of hormonal treatment in acne

Severe flare-ups before menstruation

When oral contraception is desirable

Acne not responding to conventional treatment

Polycystic ovary syndrome

Late onset acne (acne tarda)

Ovarian or adrenal hyperandrogenism

Table 2 Summary of treatment recommendations from the European acne guidelines

\begin{tabular}{|c|c|c|c|c|}
\hline Type of acne & $\begin{array}{l}\text { First-line } \\
\text { treatment }\end{array}$ & $\begin{array}{l}\text { Second-line } \\
\text { treatment }\end{array}$ & $\begin{array}{l}\text { Third-line } \\
\text { treatment }\end{array}$ & $\begin{array}{l}\text { Hormonal alternatives } \\
\text { for women }\end{array}$ \\
\hline Comedonal acne & $\begin{array}{l}\text { Topical retinoids, } \\
\text { adapalene is } \\
\text { preferred to } \\
\text { tretinoin }\end{array}$ & $\begin{array}{l}\text { Benzoyl peroxide } \\
\text { (BPO) or azelaic acid }\end{array}$ & - & Not recommended \\
\hline $\begin{array}{l}\text { Mild to moderate } \\
\text { papulopustular acne }\end{array}$ & $\begin{array}{l}\text { BPO + adapalene } \\
\text { (f.c.) or BPO + } \\
\text { clindamycin (f.c.) }\end{array}$ & $\begin{array}{l}\text { BPO or azelaic } \\
\text { acid or systemic } \\
\text { antibiotic }+ \text { adapalene }\end{array}$ & $\begin{array}{l}\text { Isotretinoin or tretinoin + } \\
\text { topical erythromycin (f.c.); } \\
\text { or systemic antibiotics + BPO; } \\
\text { or systemic antibiotics + azelaic } \\
\text { acid; systemic antibiotics + } \\
\text { adapalene + BPO (f.c.) }\end{array}$ & Not recommended \\
\hline $\begin{array}{l}\text { Severe papulopustular } \\
\text { acne and mild nodular } \\
\text { acne }\end{array}$ & $\begin{array}{l}\text { Systemic } \\
\text { isotretinoin }\end{array}$ & $\begin{array}{l}\text { Systemic antibiotics + } \\
\text { adapalene; systemic } \\
\text { antibiotics + azelaic } \\
\text { acid; or systemic } \\
\text { antibiotics + BPO + } \\
\text { adapalene (f.c.) }\end{array}$ & Systemic antibiotics + BPO & $\begin{array}{l}\text { Hormonal antiandrogens }+ \\
\text { topical treatment or } \\
\text { systemic antibiotics } \\
\text { (topical treatment is } \\
\text { preferred) }\end{array}$ \\
\hline $\begin{array}{l}\text { Severe nodular } \\
\text { acne and conglobate } \\
\text { acne }\end{array}$ & $\begin{array}{l}\text { Systemic } \\
\text { isotretinoin }\end{array}$ & $\begin{array}{l}\text { Systemic antibiotics }+ \\
\text { azelaic acid }\end{array}$ & $\begin{array}{l}\text { Systemic antibiotics }+ \\
\text { BPO; or systemic antibiotics + } \\
\text { adapalene; or systemic } \\
\text { antibiotics + BPO + } \\
\text { adapalene (f.c.) }\end{array}$ & $\begin{array}{l}\text { Hormonal antiandrogens }+ \\
\text { systemic antibiotics } \\
\text { (consider as third line } \\
\text { treatment) }\end{array}$ \\
\hline
\end{tabular}

Abbreviation: f.c., fixed combination. 
and even retinoids. A course of 3 months is often necessary before experiencing much improvement and benefit from treatment. ${ }^{33}$ Drugs used in the hormonal treatment of acne fall into four major categories: 1) AR blockers, 2) oral contraceptives, suppressing androgen production by the ovaries, 3) glucocorticoids, suppressing adrenal androgen production, and 4 ) enzyme inhibitors ( $5 \alpha$-reductase inhibitors; Table 3$) .5$

\section{Androgen receptor blockers Spironolactone}

It is a well-known AR blocker used for $>30$ years in the treatment of acne. It combines antiandrogenic effect along with antialdosterone effect as well as being a week progestin. Spironolactone mediates its action through the following: ${ }^{34}$

1. Nuclear blockage of ARs in a competitive action to testosterone and DHT preventing their binding and actions.

2. Decreasing testosterone formation by inhibiting Type 2 17B-HSD enzyme.

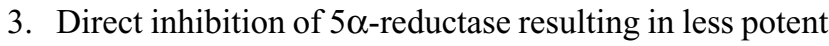
DHT formation.

4. Increasing the level of SHBG and hence decreasing the levels of circulating testosterone.

The usual dosage for the treatment of acne is $50-200 \mathrm{mg}$ daily and usually administered after food. Despite the long use of spironolactone in acne and due to the limited number of literature studies, the efficacy of spironolactone remains to be considered intermediate. ${ }^{35}$

Impotence, decreased libido, and gynecomastia are side effects that limited male use of spironolactone; however, it is generally safer and well accepted to use in women. ${ }^{36}$ Hyperkalemia is an electrolyte imbalance that should be monitored and checked periodically for those on spironolactone therapy ${ }^{37}$ Potassium monitoring should be done frequently and on regular basis while on spironolactone and the drug should be immediately stopped in hyperkalemia of concern. Gastrointestinal side effects are nausea, vomiting, anorexia, and diarrhea, which are not infrequent among users. Pregnancy is a contraindication for using spironolactone and there is an increased risk of feminization of male fetus as well as increased risk of hypospadias. Due to the risk of birth defects and the reduction of side effects, spironolactone should be used in conjunction with oral contraceptives. ${ }^{38}$ Topical spironolactone $5 \%$ has been investigated for its local antiandrogen effects but much larger controlled studies are required to assess its efficacy and safety in the future. ${ }^{39}$

\section{Cyproterone acetate}

Cyproterone acetate (CPA) is one of the earliest and most studied antiandrogens. CPA exhibits the two properties

Table 3 Different therapies and their mechanism of action and possible side effects

\begin{tabular}{|c|c|c|c|c|}
\hline & COC & Spironolactone & Cyproterone acetate & Flutamide \\
\hline \multirow[t]{6}{*}{ Mechanism of action } & Decreases $5 \alpha$-reductase & Decreases & Blocks testosterone & Blocks nuclear \\
\hline & activity & $5 \alpha$-reductase activity & receptors & binding of \\
\hline & Decreases free & Decreases Free & Decreases secretion of & androgens \\
\hline & testosterone & testosterone & gonadotropins & \\
\hline & Decreases sebaceous & Decreases Sebaceous & & \\
\hline & gland size and activity & gland size and activity & & \\
\hline \multirow[t]{9}{*}{ Side effects } & Gl disorders & Hypercalcemia & Headache & Hematological \\
\hline & Spotting & Breast tenderness & Breast tenderness & disorders \\
\hline & & & & Muscle cramps \\
\hline & Headache & Menstrual irregularities & Menstrual & Gynecomastia \\
\hline & Breast tenderness & & irregularities & Acute liver failure \\
\hline & & & Fluid retention & \\
\hline & Fluid retention & Hypotension & Liver dysfunction & \\
\hline & Depression & Reduced libido & Blood clotting & \\
\hline & & Hyperkalemia & disorders & \\
\hline \multirow[t]{10}{*}{ Contraindications } & Smoking in age & Risk of estrogen- & History of meningioma & Liver disease \\
\hline & $>35$ years & dependent malignancy & & \\
\hline & CVS diseases & & & \\
\hline & Hematological & & Liver disease & \\
\hline & disorders & & Hematological & \\
\hline & & & disorders & \\
\hline & $\mathrm{BMI} \geq 35$ & & Severe diabetes & \\
\hline & Migraine & & Sickle cell anemia & \\
\hline & Risk of estrogen-dependent & & Severe depression & \\
\hline & malignancy & & & \\
\hline
\end{tabular}

Abbreviations: COC, combined oral contraceptives; GI, gastrointestinal; CVS, cardiovascular; BMI, body mass index. 
of being an antiandrogen and a progestin. It is very effective when used as a monotherapy showing acne improvement rates of $75 \%$ and up to $90 \%$ of women in doses of $50-100 \mathrm{mg} / \mathrm{d}$ from days 1 to 10 of the menstrual cycle. ${ }^{40}$ Despite its monotherapy high rates of clearance, it is usually combined with estrogen in the oral contraceptive pill (OCP) in doses of $2 \mathrm{mg}$ with $35 \mu \mathrm{g}$ of ethinyl estradiol. CPA inhibits androstenedione formation from DHEA with a subsequent decrease in sebum production. Hepatotoxicity, feminization of male fetus, represents the most important side effect besides breast tenderness and gastric upset manifestations of nausea and vomiting. ${ }^{41}$

\section{Flutamide}

Flutamide is approved for the treatment of cancer prostate and is likewise effective to treat acne, androgenetic alopecia, and hirsutism. It interferes with binding of DHT to its receptors and recently was established that it can increase the breakdown of active testosterone to inactive metabolites. Doses range from as low as $62.5-500 \mathrm{mg} / \mathrm{d} .{ }^{42}$ Side effects include breast tenderness, gastrointestinal upset, and decreased libido. Serious side effects include pseudohermaphrodite condition and signs of feminization in the male fetus as well as fatal hepatitis, which is dose and age related; therefore, regular liver function tests are necessary although such side effects limit its use in acne. ${ }^{43}$

\section{Drugs acting on adrenal androgen production}

Oral corticosteroids if used in high doses might help patients with inflammatory signs of acne despite any hormonal causes, while oral low-dose steroids suppress adrenal activity in patients with proven adrenal hyperactivity. Elevated levels of DHEA, 17 hydroxyprogesterone, and androstenedione are positive tests and indicative of the diagnosis. ${ }^{8}$ Deficiency of 21 hydroxylase and less often eleven hydroxylase enzymes shifts the hormonal production of the adrenals toward androgens instead of steroids. In such a case, a low-dose prednisone $(2.5-5 \mathrm{mg})$ or a low-dose dexamethasone $(0.25-0.75 \mathrm{mg})$ once at bedtime is thought to counteract the unopposed ACTH production of androgens. This nighttime dose is thought to suppress the early morning peak of ACTH and meanwhile inhibit androgen formation. ${ }^{44}$

Monitoring long-term side effects of steroids such as osteoporosis and blood sugar levels is mandatory, and longterm use of $>6$ months is not preferred. The risk of adrenal suppression should be tested every 2 months using the ACTH stimulation test. ${ }^{4}$

\section{Ovarian androgen blockade}

\section{Combined oral contraceptives}

Combinations of both estrogen and progestins exert their action through negative feedback on the pituitary gonadal axis inhibiting $\mathrm{LH} / \mathrm{FSH}$ release and the subsequent ovulation and LH-related androgen production. Progestins are included basically to avoid the risk of developing endometrial cancer imposed by the unopposed estrogen action. It is initiated from day 1 of the menstrual cycle and for 21 days on/7 days off fashion, for five to six cycles, after making sure that pregnancy test is negative. ${ }^{45}$

The estrogen component in combined oral contraceptives (COCs) is almost always ethinyl estradiol and rarely mestranol. The progestin components vary and include CPA, chlormadinone, drospirenone, and derivatives of 19 nortestosterone that cross-react with testosterone receptors as well. The latter testosterone derivative progestins have androgen-like effects that might trigger acne, create breast tenderness, irritability, and fatigue. ${ }^{4}$

Only progestins with low androgenetic properties (norgestimate and desogestrel) or no androgenic properties (CPA, chlormadinone, and drospirenone) are being used in combination. Drospirenone is the only progestin approved by the Food and Drug Administration (FDA), which blocks the AR and is truly antiandrogenic, even without the addition of estrogen. ${ }^{38}$

Estrogens are sebosuppressive (decrease sebum production) in high doses only which otherwise would increase the risk of side effects. However, most of the COCs in the market today contain lower doses of estrogens $(20-50 \mu \mathrm{g})$, which are not sebosuppressive but can inhibit androgens by several mechanisms: ${ }^{7}$

1. Suppress secretion of pituitary gonadotropins, inhibit ovulation, and thus inhibit androgen production by the ovaries.

2. Block the AR.

3. Increase the liver production of SHBG and reducing circulating testosterone.

4. Progestins contained in the COCs suppress $5 \alpha$-reductase and thus inhibit the formation of potent androgens.

COCs are the first line of treatment for women presenting with PCOS. The choice of the combination is important since some pills contain progestins with more androgenic effect (levonorgestrel and norgestrel) and should be avoided while other combinations contain third generation progestins with less androgenic effect (norgestimate, gestodene, and desogestrel). ${ }^{33}$ 
One of the most important safety considerations while using OCPs is vascular thromboembolism (venous and arterial). The risk of thromboembolism is increased three times in users than nonusers of the pills. These vascular events are much less with the new formulations of OCPs containing lowdose estrogens and in healthy nonsmokers who are 35 years of age or younger. The frequency of venous thromboembolism is at its highest during the first year of use. ${ }^{45}$

Based on WHO recommendations, the use of COCs is absolutely contraindicated in pregnancy, history of thromboembolism, liver disease, and in smokers aged $\geq 35$ years, while relative contraindications include breastfeeding, hypertension, migraine, and existing malignancies. Moreover, certain conditions might be worsened by contraceptives such as insulin resistance and is contraindicated in diabetic patients, clotting disorders, and in patients with increased risk of breast cancer. ${ }^{46}$

\section{Gonadotropin-releasing hormone agonists}

These are analogs of gonadotropin-releasing hormone that inhibit the cyclic release of LH/FSH from the ovaries and result in an induced state of anovulation, suppressing both estrogen and androgen production. ${ }^{47}$ They are available in the form of nasal sprays, subcutaneous injection, intramuscular injection, and as a subcutaneous implant. To date, no much controlled studies are available on gonadotropin-releasing hormone due to their high cost and partly due to their menopausal effects (bleeding, osteoporosis, and flushes). Lactation, vaginal bleeding, and pregnancy are contraindications for their use. ${ }^{48}$

\section{Insulin-sensitizing agents}

Insulin resistance decreases uptake of insulin by cells and results in increased levels of insulin. Insulin resistance plays an important role by increasing the pool of androgens by the ovaries and adrenals and by decreasing the synthesis of SHBG resulting in a state of hyperandrogenemia. ${ }^{49}$ Metformin is used for acne in association with PCOS, HAIRAN syndrome, obese patients, or biochemical evidence of hyperinsulinemia, and it is important to note that metformin does not cause hypoglycemia. Treatment is started with a dose of $500 \mathrm{mg}$ and up to $2,000 \mathrm{mg} / \mathrm{d}$. There is no limit to how long metformin is used, but it should be discontinued in 6 months if no improvements are seen. Most side effects are dose dependent and include nausea and vomiting, limiting its use to postprandial intake and starting with a low dose of $250 \mathrm{mg} .{ }^{50}$

\section{Conclusion}

Hormonal therapies are reserved not only for patients with biochemical markers of hyperandrogenism but also for the severe, resistant cases as well as for those patients who show an unpredictable course and high frequency of acne bouts without hyperandrogenemia. Hormonal evaluation is mandatory and reserved for the more resistant cases and for those who fail to respond to conventional therapies. A decent comprehension of the hormonal milieu in the human body can pinpoint toward an optimal, faster, and more appropriate treatment of acne. It is of much importance for the dermatologists to get acquainted of available hormonal treatments, their optimal modes of use, and their relative and absolute contraindications.

\section{Disclosure}

The author reports no conflicts of interest in this work.

\section{References}

1. Simpson NB, Cunliffe WJ. Disorders of the sebaceous glands. In: Burns T, Breathnach S, Cox N, Griffiths C, editors. Rook's Text Book of Dermatology. 7th ed. Oxford: Blackwell Science; 2004:1-75.

2. Suh DH, Kwon HH. What's new in the physiopathology of acne. Br J Dermatol. 2015;172(suppl 1):13-19.

3. Gollnick H, Cunliffe W, Bernson D, et al. Management of acne. J Am Acad Dermatol. 2008;49:20-25.

4. Lakshmi C. Hormone therapy in acne. Indian J Dermatol Venereol Leprol. 2013;79:322-337.

5. Gollnick HP, Dreno B. Pathophysiology and management of acne. J Eur Acad Dermatol Venereol. 2015;29(suppl 4):1-2.

6. Lai JJ, Chang P, Lai KP, Chen L, Chang C. The role of androgen and androgen receptor in the skin-related disorders. Arch Dermatol Res. 2012;304:499-510.

7. Husein-ElAhmed H. Management of acne vulgaris with hormonal therapies in adult female patients. Dermatol Ther. 2015;28(3):166-172.

8. Bettoli V, Zauli S, Virgili A. Is hormonal treatment still an option in acne today? Br J Dermatol. 2015;172(suppl 1):37-46.

9. Schneider MR, Paus R. Sebocytes, multifaceted epithelial cells: lipid production and holocrine secretion. Int J Biochem Cell Biol. 2010;42(2):181-185.

10. Deplewski D, Rosenfield RL. Role of hormones in pilosebaceous unit development. Endocr Rev. 2000;21(4):363-392.

11. Nast A, Dreno B, Bettoli V, et al. European evidence-based (S3) guidelines for the treatment of acne. J Eur Acad Dermatol Venereol. 2012;26:1-29.

12. Beylot C, Auffret N, Poli F, et al. Propionibacterium acnes: an update on its role in the pathogenesis of acne. J Eur Acad Dermatol Venereol. 2014;28(3):271-278.

13. Gollnick HP. From new findings in acne pathogenesis to new approaches in treatment. J Eur Acad Dermatol Venereol. 2015;29(suppl 5):1-7.

14. Toossi P, Azizian Z, Yavari H, Fakhim TH, Amini SH, Enamzade R. Serum 25-hydroxy vitamin D levels in patients with acne vulgaris and its association with disease severity. Clin Cases Miner Bone Metab. 2015;12(3):238-242.

15. Balachandrudu B, Niveditadevi V, Rani TP. Hormonal pathogenesis of acne - simplified. Int J Sci Stu. 2015;3:183-185.

16. Chen W, Thibout D, Zouboulis CC. Cutaneous androgen metabolism: basic research and clinical perspective. J Invest Dermatol. 2002;119:992-1007. 
17. Zouboulis CC, Jourdan E, Picardo M. Acne is an inflammatory disease and alterations of sebum composition initiate acne lesions. J Eur Acad Dermatol Venereol. 2014;28(5):527-532.

18. Thiboutot D. Acne: hormonal concepts and therapy. Clin Dermatol. 2004;22(5):419-428.

19. Melnik BC, John SM, Plewig G. Acne: risk indicator for increased body mass index and insulin resistance. Acta Derm Venereol. 2013;93(6):644-649.

20. Smith TM, Gilliland K, Clawson GA, Thiboutot D. IGF-1 induces SREBP-1 expression and lipogenesis in SEB-1 sebocytes via activation of the phosphoinositide 3-kinase/Akt pathway. J Invest Dermatol. 2008;128:1286-93.

21. Arlt W, Stewart PM. Adrenal corticosteroid biosynthesis, metabolism, and action. Endocrinol Metab Clin North Am. 2005;34(2):293-313.

22. Böhm M, Ehrchen J, Luger TA. Beneficial effects of the melanocortin analogue Nle4-D-Phe7- $\alpha-M S H$ in acne vulgaris. J Eur Acad Dermatol Venereol. 2014;28(1):108-111.

23. Shibata M, Katsuyama M, Onodera T, Ehama R, Hosoi J, Tagami H. Glucocorticoids enhance Toll-like receptor 2 expression in human keratinocytes stimulated with Propionibacterium acnes or proinflammatory cytokines. J Invest Dermatol. 2009;129(2):375-82.

24. Arora MK, Yadav A, Saini V. Role of hormones in acne vulgaris. Clin Biochem. 2011;44(13):1035-1040.

25. Balen AH, Laven JS, Tan SL, Dewally D. Ultrasound assessment of the polycystic ovary: international consensus definition. Hum Reprod Update. 2003;9:505-514.

26. Barbieri RL, Smith S, Ryan KJ. The role of hyperinsulinemia in the pathogenesis of ovarian hyperandrogenism. Fertil Steril. 1988;50(2):197-212.

27. Rosenfield RL. Current concepts of polycystic ovary syndrome. Baillières Clin Obstet Gynaecol. 1997;11(2):307-333.

28. Zaenglein AL, Pathy AL, Schlosser BJ, et al. Guidelines of care for the management of acne vulgaris. JAm Acad Dermatol. 2016;74(5):945.e-973.e.

29. Sato T, Kurihara H, Akimoto N, Noguchi N, Sasatsu M, Ito A. Augmentation of gene expression and production of promatrix metalloproteinase 2 by Propionibacterium acnes-derived factors in hamster sebocytes and dermal fibroblasts: a possible mechanism for acne scarring. Biol Pharm Bull. 2011;34(2):295-299.

30. Lin-Su K, Nimkarn S, New MI. Congenital adrenal hyperplasia in adolescents: diagnosis and management. Ann NY Acad Sci. 2008;1135:95-98.

31. Eric K, Ricardo A. Ovarian hormones and andrenal androgens during a women's life span. J Am Acad Dermatol. 2001;45:105-115.

32. Tyler KH, Zirwas MJ. Pregnancy and dermatologic therapy. J Am Acad Dermatol. 2013;68(4):663-671.

33. Harper JC. Use of oral contraceptives for management of acne vulgaris: practical considerations in real world practice. Dermatol Clin. 2016;34(2):159-165.

34. Sato K, Matsumoto D, Iizuka F, et al. Anti-androgenic therapy using oral spironolactone for acne vulgaris in Asians. Aesthetic Plast Surg. 2006;30(6):689-694.
35. Brown J, Farquhar C, Lee O, Toomath R, Jepson RG. Spironolactone versus placebo or in combination with steroids for hirsutism and/or acne. Cochrane Database Syst Rev. 2009;15(2):CD000194.

36. Yemisci A, Gorgulu A, Piskin S. Effects and side-effects of spironolactone therapy in women with acne. J Eur Acad Dermatol Venereol. 2005; 19:163-166.

37. Shaw JC. Acne: effect of hormones on pathogenesis and management. Am J Clin Dermatol. 2008;3(8):571-578.

38. George R, Clarke S, Thiboutot D. Hormonal therapy for acne. Semin Cutan Med Surg. 2008;27(3):188-196

39. Layton AM. Top ten list of clinical pearls in the treatment of acne vulgaris. Dermatol Clin. 2016;34(2):147-157.

40. Van Wayjen R, van den Ende A. Experience in the long-term treatment of patients with hirsutism and/or acne with cyproterone acetate-containing preparations: efficacy, metabolic, andendocrine effects. Exp Clin Endocrinol Diabetes. 1995;103(4):241-251.

41. Thiboutot D, Archer DF, Lemay A, Ballagh SA, Nichols M, Weber ME. A randomized, controlled trial of a low-dose contraceptive containing $20 \mathrm{mcg}$ of ethinyl estradiol and $100 \mathrm{mcg}$ of levonorgestrel for acne treatment. Fertil Steril. 2001;76:461-468.

42. Adalatkhah H, Pourfarzi F, Sadeghi-Bazargani H. Flutamide versus a cyproterone acetate-ethinyl estradiol combination in moderate acne: a pilot randomized clinical trial. Clin Cosmet Investig Dermatol. 2011;4: 117-121.

43. Lowenstein EJ. Diagnosis and management of the dermatologic manifestations of the polycystic ovary syndrome. Dermatol Ther. 2006;19(4): 210-223.

44. Nast A, Ernst H, Rosumeck S, Erdmann R, Jacobs A, Sporbeck B. Risk of complications due to anticoagulation during dermatosurgical procedures: a systematic review and meta-analysis. J Eur Acad Dermatol Venereol. 2014;28(12):1603-1609.

45. Arrington EA, Patel NS, Geranker K, Feldman SR. Combined oral contraceptives for the treatment of acne: a practical guide. Cutis. 2012;90(2):83-90.

46. Chan CS, Harting M, Rosen T. Systemic and barrier contraceptives for the dermatologist: a review. Int J Dermatol. 2009;48:795-814.

47. Faloia E, Filipponi S, Mancini V, Morosini P, De Pirro R. Treatment with a gonadotropin-releasing hormone agonist in acne or idiopathic hirsutism. J Endocrinol Invest. 1993;16(9):675-677.

48. Ghosh S, Chauduri S, Jain VK, Aggarwal K. Profiling and hormonal therapy for acne in women. Indian J Dermatol. 2014;59(2):107-115.

49. Wang QY, Song Y, Huang W. Comparison of drospirenone- with cyproterone acetate-containing oral contraceptives combined with metformin and lifestyle modifications in women with polycystic ovary syndrome and metabolic disorders: a prospective randomized control trial. Chin Med J. 2016;129(8):883-890.

50. Bubna AK. Metformin - for the dermatologist. Indian J Pharmacol. 2016;48(1):4-10.
Clinical, Cosmetic and Investigational Dermatology

\section{Publish your work in this journal}

Clinical, Cosmetic and Investigational Dermatology is an international, peer-reviewed, open access, online journal that focuses on the latest clinical and experimental research in all aspects of skin disease and cosmetic interventions. This journal is included on PubMed. The manuscript management system is completely online

\section{Dovepress}

and includes a very quick and fair peer-review system, which is all easy to use. Visit http://www.dovepress.com/testimonials.php to read real quotes from published authors 